\title{
Myocardial Infarction with Non-obstructive Coronary Arteries-MINOCA
}

\author{
Sahela Nasrin', Masuma Jannat Shafi ${ }^{2}$
}

\begin{abstract}
Myocardial Infarction with Non-obstructive Coronary Arteries-MINOCA is a clinical syndrome that encompasses a subgroup of heterogeneous patients who present with myocardial infarction yet do not have any significant coronary artery obstruction on angiogram. From several studies it is understood that MINOCA has a $8.8 \%$ prevalence of all Myocardial Infarction (MI) presentations, with no characteristic distinguishing clinical features when compared with MI-CAD( Coronary artery disease), except for patients being younger with a female preponderance \& less likely to have hyperlipidemia. The prognosis is extremely variable, depending on the causes of MINOCA. Clinical history, echocardiography, coronary angiography, and left ventriculography represent the first-level diagnostic investigations.
\end{abstract}

Key words: MINOCA, myocardial infarction, non-obstructive coronary arteries.

\section{INTRODUCTION}

MINOCA-myocardial infarction with nonobstructive coronary arteries, the name itself describes that there is a myocardial infarction without significant obstructive coronary artery disease. Therefore this review was done to address the following objectives:

- Investigate the degree of stenosis

- Determine the association of MINOCA with any specific type of acute coronary syndrome (ACS).

- Know the influence of age, gender and ethnicity on MINOCA.

- Study the potential pathophysiological mechanisms underlying this disorder.

- Know the therapy of MINOCA

- Assess the prognosis of MINOCA

According to European Society of Cardiology (ESC) position paper on myocardial infarction with non-obstructive coronary arteries, the diagnosis of
MINOCA is made immediately upon coronary angiography in a patients presenting with features consistent with an acute myocardial infarct along with features of non-obstructive coronary arteries on angiography, as detailed by the following criteria. ${ }^{1}$

\section{(1) AMI criteria: ${ }^{2}$}

- Positive cardiac biomarker (preferably cardiac troponin) defined as a rise and/or fall in serial levels, with at least one value above the $99^{\text {th }}$ percentile upper reference limit. and

- Corroborative clinical evidence of infarction evidenced by at least one of the following:

- Symptoms of ischaemia

- New or presumed new significant ST-T changes or new LBBB

- Development of pathological Q waves

- Imaging evidence of new loss of viable myocardium or new RWMA

- Intracoronary thrombus evident on angiography or at autopsy

\section{Authors' information:}

${ }^{1}$ Dr. Sahela Nasrin, MBBS, MCPS (Med), MD (Card), Associate Consultant \& Assistant Professor, Ibrahim Cardiac Hospital \& Research Institute, Shahbag, Dhaka-1000.

2 Dr. Masuma Jannat Shafi, MBBS, D Card (BSMMU), Registrar \& specialist in cardiology, Ibrahim Cardiac Hospital \& Research Institute, Shahbag, Dhaka-1000.

Correspondence: Dr. Sahela Nasrin, Cell: +8801766089094, Email: nasrin_jhumur@hotmail.com 


\section{(2) Non-obstructive coronary arteries on angiography:}

- Defined as the absence of obstructive CAD on angiography, (i.e. no coronary artery stenosis $\geq 50 \%$ ), in any potential infarct-related artery.

- This includes both patients with:

D Normal coronary arteries (no stenosis $<30 \%$ )

D Mild coronary atheromatosis (stenosis $>30 \%$ but $<50 \%$ ).

\section{(3) No clinically overt specific cause for the} acute presentation:

- At the time of angiography, the cause and thus a specific diagnosis for the clinical presentation is not apparent.

- Accordingly, there is a necessity to further evaluate the patient for the underlying cause of the MINOCA presentation.

- LBBB-left bundle branch block. RWMA-regional wall motion abnormality.

Myocardial infarction with no obstructive coronary atherosclerosis (MINOCA) is a syndrome with different causes $^{3}$ characterized by clinical evidence of MI with normal or near normal-coronary arteries on angiography (stenosis severity $<50 \%$ ). Data from large MI registries suggest a prevalence between 5 and $25 \%,{ }^{3-6}$ but the most recent study, in a contemporary cohort of patients, reported a prevalence of $8.8 \% .^{7}$

Among patients presenting with ST-segment elevation myocardial infarction (STEMI), the majority (almost 90\%) has coronary artery occlusion by angiography if it was undertaken within ${ }^{4}$ hours of onset of chest pain. ${ }^{8}$ In contrast, in patients presenting with NSTEMI, approximately $26 \%$ have evidence of coronary artery occlusion when angiography was performed within 24 hours of symptom onset. ${ }^{9}$ In both of these landmark studies, ${ }^{8,9}$ more than $90 \%$ of the acute MI patients had angiographic evidence of obstruction. Approximately $10 \%$ of patients presenting with acute MI (AMI) have no significant obstructive
CAD. A diagnosis of MINOCA can be made in patients presenting with features of AMI but a coronary angiogram demonstrating non-obstructive CAD. ${ }^{1}$ An analysis of patients with NSTEMI included in the CRUSADE (Can Rapid risk stratification of Unstable angina patients Suppress Adverse outcomes with Early implementation of the ACC/AHA guidelines) registry showed that female sex and younger age were independent clinical predictors of MINOCA. ${ }^{4}$

In MINOCA, the median age was 55 years \& $40 \%$ were women. About $10-25 \%$ of women \& $6-10 \%$ of men with Acute Coronary Syndrome (ACS) have MINOCA. The higher rates in women has been observed in several trials, such as the CRUSADE trial, the WISE (Women's Ischemia Syndrome Evaluation) trial \& GUSTO IIb (The Global Use of Strategies to Open Occluded Coronary Arteries in Acute Coronary Syndromes) trial, etc. ${ }^{10}$ Black women had a higher likelihood of no obstruction at angiography compared with other racial/ethnic groups of women (59\% vs. $27 \%$ ). Endothelial dysfunction, positive remodeling, blood disorders, like sickle-cell disease ${ }^{11}$ \& hemoglobinopathies have been postulated as causative in black women. Asian patients were less likely to have no obstruction at angiography compared to other groups. ${ }^{12}$ In comparison to those with myocardial infarction associated with obstructive coronary artery disease (MI-CAD), the patients with MINOCA were more likely to be younger and female but less likely to have hyperlipidemia, although other cardiovascular risk factors were similar.

\section{CAUSES OF MINOCA}

\section{Epicardial Causes}

\section{- Coronary artery spasm}

Coronary artery spasm (CAS) represents an important epicardial cause of MINOCA. It usually occurs at a localized segment of an epicardial artery, but sometimes involves two or more segments of the same (multifocal spasm) or different (multi-vessel spasm) coronary arteries, or may involve diffusely one or multiple coronary 
branches. ${ }^{13}$ The prevalence ranges between 3 and $95 \%$ of MINOCA patients; this wide difference depends on the stimuli used to trigger spasm, definitions of spasm, and ethnic reasons. ${ }^{14}$ Provocative spasm testing has demonstrated inducible spasm in $27 \%$ of patients with MINOCA suggesting that it is a common and an important pathogenetic mechanism in MINOCA. ${ }^{14}$

\section{- Non-obstructive coronary atherosclerosis with positive remodeling/plaque disruption}

Atherosclerotic plaque disruption is a frequent cause of MINOCA. Plaque disruption is comprised within type-1 AMI in the Universal Definition of Myocardial Infarction, even when no thrombus can be found. ${ }^{2}$ Within the Universal definition document, MINOCA comprises $5-20 \%$ of all type-1 AMI cases. The term disruption encompasses imaging and pathologic findings of plaque rupture, ulceration, or erosion. Intraplaque haemorrhage may also play a role. Two independent studies using intravascular ultrasound identified plaque rupture or ulceration in $40 \%$ of patients with MINOCA. ${ }^{15,16}$ Another epicardial cause of MINOCA is the presence of eccentric plaques with positive remodeling resulting in lack of obstructive CAD. These lesions frequently show characteristics of vulnerability: large lipid pool and thin fibrous cap, ${ }^{17}$ which may increase the susceptibility to plaque rupture. ${ }^{18}$

\section{Microvascular Causes}

\section{- Takotsubo syndrome}

A microvascular cause of MINOCA is represented by Takotsubo syndrome (TS). Its prevalence is reported to range between 1.2 and $2.2 \%$ of all ACS. Although several etiopathogenetic mechanisms have been proposed (e.g. multi-vessel epicardial spasm, catecholamine-induced myocardial stunning, spontaneous coronary thrombus lysis, and acute microvascular spasm).

\section{- Coronary microvascular spasm}

Coronary micro-vascular spasm is characterized by transient transmural myocardial ischemia, as indicated by ST-segment changes, during spontaneous or provoked angina, in the presence of normal epicardial coronary arteries. It may be considered as unstable presentation of microvascular angina. ${ }^{19}$ About $25 \%$ of patients with ACS and no obstructive CAD have evidence of microvascular spasm, although an increase of troponin is unfrequent. ${ }^{20}$

\section{- Myocarditis mimicking MI}

In about one-third of patients, MINOCA is caused by acute myocarditis mimicking MI. Adenoviruses, parvovirus B19 (PVB19), human herpes virus 6, and Coxsackie virus are considered the most common causes of viral myocarditis. Previous studies suggested that the clinical presentation is related to the type of virus. ${ }^{21}$ In particular, PVB19 myocarditis may mimic MINOCA.

\section{- Coronary Embolism}

Coronary embolism should be suspected in patients with MINOCA and one of the following conditions associated with high risk of systemic embolism: prosthetic heart valves, chronic atrial fibrillation, dilated cardiomyopathy with apical thrombus, infective endocarditis, and myxoma, papillary fibroelastoma, iatrogenic air emboli, calcified valves. ${ }^{22,23}$ coronary emboli may occur from coronary or systemic arterial thrombi. Hereditary thrombophilia disorders include Factor $\mathrm{V}$ Leiden thrombophilia, Protein $\mathrm{S}$ and $\mathrm{C}$ deficiencies. Thrombophilia screening studies in patients with MINOCA have reported a $14 \%$ prevalence of these inherited disorders. ${ }^{11}$ Acquired thrombophilia disorders should also be considered such as the antiphospholipid syndrome and myeloproliferative disorders, although these have not been systematically investigated in MINOCA. In all these cases, a hypercoagulable state might predispose to thrombus formation. ${ }^{24}$

\section{Clinical assessment (Diagnosis of MINOCA and implication Cardiac magnetic resonance imaging):}

MINOCA is a working diagnosis and should lead the treating physician to investigate underlying causes, analogous to heart failure. This review article outlines suggestions for diagnostic testing in order to identify or exclude potential etiologies. 
Left ventriculography or echocardiography should be performed in the acute setting to assess wall motion. This will aid the clinician in determining whether takotsubo cardiomyopathy is a diagnostic consideration. The most common causes of MINOCA that the treating clinician must consider are plaque rupture or erosion, coronary artery spasm, thromboembolism, coronary dissection, takotsubo cardiomyopathy, unrecognized myocarditis, and other forms of type-2 myocardial infarction, in which a condition other than coronary plaque instability contributes to an imbalance between myocardial oxygen supply and demand and cause myocardial necrosis, such as tachyarrhythmia, haemorrhage, sepsis, and hypertensive crisis.

Cardiac magnetic resonance (CMR) imaging is the key diagnostic tool to be employed in MINOCA patients. Late gadolinium enhancement (LGE), when present, permits localization of the area of myocardial damage and provides insight into mechanisms. For example, an area of LGE in the bed of subendocardium suggests an ischaemic cause of injury, although it does not identify the particular cause of ischaemia (plaque disruption, vasospasm, thromboembolism, or dissection), while a sub-epicardial localization speaks in favour of cardiomyopathy. In other patients, a non-ischaemic appearance of LGE may suggest a diagnosis of myocarditis or an infiltrative disorder. Imaging for myocardial oedema and contractile function may also help localize the area of injury, though with less mechanistic insight.

Intracoronary imaging at the time of cardiac catheterization with intravascular ultrasound (IVUS) or optical coherence tomography (OCT) may be useful to identify atherosclerotic plaque disruption and plaque erosion as well as coronary dissection or thrombosis, which may not have been appreciated during angiography. An alternative consideration is that the troponin rise is not indicative of AMI and is, instead, due to other causes, such as, pulmonary embolism or myocarditis. These alternate causes should be reconsidered when CMR is normal.

\section{DIAGNOSTIC ALGORITHM}

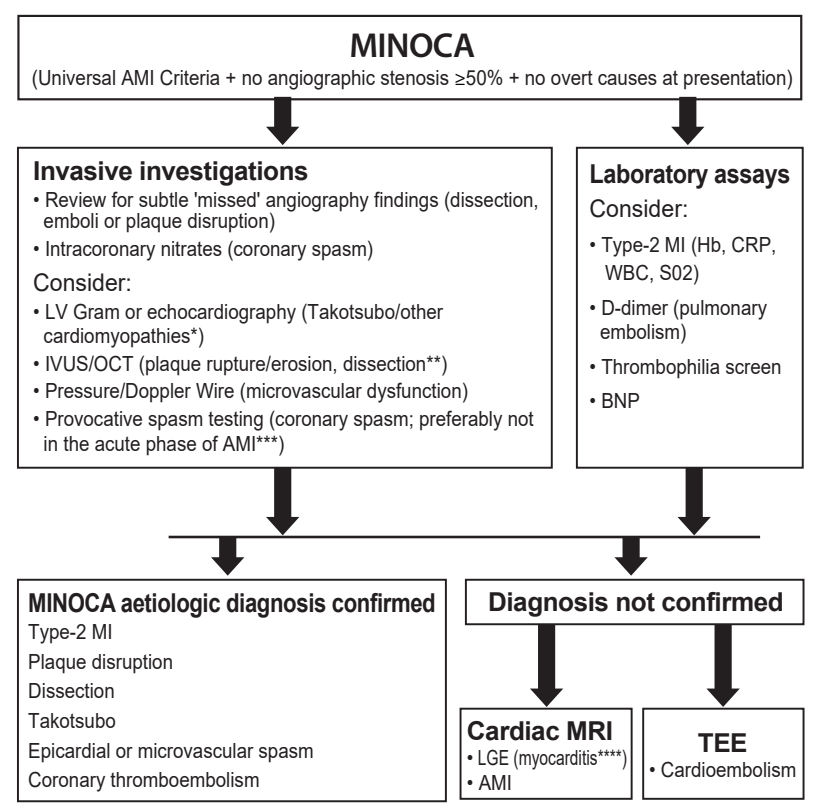

Fig. 1: Diagnostic algorithm of MINOCA (Adapted from Agewall et. al.')

\section{PROGNOSIS OF MINOCA}

The prognosis of MINOCA is not as benign as reported by early cohort studies as commonly assumed by physicians. ${ }^{5}$ Indeed, the rate of all-cause mortality during admission and at 12-month follow-up ranged between 0.1 and $2.2 \%$ and between 2.2 and $4.7 \%$, respectively. ${ }^{25,26}$ Of note, a recent retrospective analysis of patients enrolled in the ACUITY trial ${ }^{7}$ showed that, compared with NSTEMI patients with obstructive CAD, patients with MINOCA had a higher adjusted risk of mortality at 1 year (5.2 vs. $1.6 \%$; HR 3.44, CI 1.05-11.28; $\mathrm{P}=0.04)$. All-cause mortality at 12-month was lower in MINOCA (4.7\% [95\%CI: 2.6-6.9\%]) compared to MI-CAD $(6.7 \%$ [95\%CI: 4.3-9.0\%]). ${ }^{11}$ The risk of recurrent myocardial infarction or death in MINOCA patients is $2 \%$ up to 12 months. ${ }^{3,26-30}$

\section{TREATMENT}

Treatment of MINOCA is as for that of MI-CAD. As thrombosis and/or thromboembolism invariably play a major role in the pathogenesis of MINOCA with plaque disruption. Dual antiplatelet therapy is recommended for 1 year followed by lifetime 
single antiplatelet therapy for patients with suspected or confirmed plaque disruption as a cause of MINOCA. ${ }^{4}$ Because disruption occurs on a background of non-obstructive CAD, statin therapy is also recommended even if only a minor degree of atherosclerosis is found. Nitrates and especially calcium antagonists are must in patients with "normal" angiogram, if spasm is the culprit. B-blockers have been shown to be highly effective for reduction of chest pain. Statins \& angiotensin-converting enzyme inhibitors improve endothelial dysfunction.

\section{CONCLUSION}

Patients with MINOCA, in particular those with angiographically normal-coronary arteries, are frequently labeled as 'non-cardiac patients', thus missing the opportunity to appropriately treat patients with an outcome worse than previously believed. New data suggest that this approach may not be appropriate. Though mortality is lower than patients with obstructive CAD, it is still at alarming rates. Many of these patients, predominantly women, frequently complaining of chest pain or tightness of chest, are re-hospitalized and have relatively high rates of progression to obstructive CAD and adverse cardiac events. MINOCA should be considered as a 'working diagnosis' with multiple potential causes that require evaluation so that directed therapies may improve its guarded prognosis. In MINOCA patients without an obvious etiology after initial evaluation including echocardiography, a routine examination with CMR imaging is recommended.

\section{REFERENCES}

1. Agewall S, Beltrame JF, Reynolds HR, Niessner A, Rosano G, Caforio ALP, et al. ESC working group position paper on myocardial infarction with non-obstructive coronary arteries. Eur Heart J 2017;38(3):143-53.

2. Thygesen K, Alpert JS, White HD, Jaffe AS, Katus HA, Apple FS, et al. ESC Committee for Practice Guidelines (CPG). Third universal definition of myocardial infarction. Eur Heart J 2012;33:2551-67.

3. Bugiardini $R$, Manfrini $O$, De Ferrari GM. Unanswered questions for management of acute coronary syndrome: risk stratification of patients with minimal disease or normal findings on coronary angiography. Arch Intern Med 2006;166:1391-95.
4. Gehrie ER, Reynolds HR, Chen AY, Neelon BH, Roe MT, Gibler WB et al. Characterization and outcomes of women and men with non-ST-segment elevation myocardial infarction and nonobstructive coronary artery disease: results from the Can Rapid Risk Stratification of Unstable Angina Patients Suppress Adverse Outcomes with Early Implementation of the ACC/AHA Guidelines (CRUSADE) quality improvement initiative. Am Heart J 2009;158:688-94.

5. Bugiardini R, Merz CNB. Angina with "normal" coronary arteries: a changing philosophy. JAMA 2005;293:477-84.

6. Crea F, Camici PG, De Caterina A, Lanza GA. Chronic ischemic heart disease. In: Camm AJ, Lüscher TF, Serruys P, editors. The ESC Textbook of Cardiovascular Medicine. New York, NY: Oxford University Press; 2009. p. 657-60.

7. Planer D, Mehran R, Ohman EM, White HD, Newman JD, Xu K, Stone GW. Prognosis of patients with non-st-segment-elevation myocardial infarction and nonobstructive coronary artery disease: propensity-matched analysis from the acute catheterization and urgent intervention triage strategy trial. Circ Cardiovasc Interv 2014; 7:285-93.

8. DeWood MA, Spores J, Notske R, Mouser LT, Burroughs $R$, Golden MS, Lang HT. Prevalence of total coronary occlusion during the early hours of transmural myocardial infarction. N Engl J Med 1980;303:897-902.

9. DeWood MA, Stifter WF, Simpson CS, Spores J, Eugster GS, Judge TP, Hinnen ML. Coronary arteriographic findings soon after non-Q-wave myocardial infarction. N Engl J Med 1986;315:417-23.

10. Ramanath VS, Armstrong DF, Grzybowski M, RahnamaMohagdam S, Tamhane UU, Gordon K et al. Receipt of cardiac medications upon discharge among men \& women with acute coronary syndrome \& nonobstructive coronary artery disease. Clin Cardiol 2010;33(1):36-41.

11. Pasupathy S, Air T, Dreyer RP, Tavella R, Beltrame JF. Systematic review of patients presenting with suspected myocardial infarction \& nonobstructive coronary arteries. Circulation 2015;131(10):861-70.

12. Chokshi NP, Iqbql SN, Berger RL, Hochman JS, Feit F, Slater JN et al. Sex \& race are associated with the absence of epicardial coronary artery obstructive disease at angiography in patients with acute coronary syndromes. Clin Cardiol 2010;33(8):495-501.

13. Lanza GA, Sestito A, Sgueglia GA, Infusino F, Manolfi $M$, Crea $F$ et al. Current clinical features, diagnostic assessment and prognostic determinants of patients with variant angina. Int J Cardiol 2007;118:41-47.

14. Pristipino C, Beltrame JF, Finocchiaro ML, Hattori R, Fujita M, Mongiardo R et al. Major racial differences 
in coronary constrictor response between Japanese and Caucasians with recent myocardial infarction. Circulation 2000; 101:1102-08.

15. Reynolds HR, Srichai MB, Iqbal SN, Slater JN, Mancini GB, Feit $F$, et al. Mechanisms of myocardial infarction in women without angiographically obstructive coronary artery disease. Circulation 2011;124:1414-25.

16. Ouldzein H, Elbaz M, Roncalli J, Cagnac R, Carrie' $D$, Puel J, Alibelli-Chemarin MJ. Plaque rupture and morphological characteristics of the culprit lesion in acute coronary syndromes without significant angiographic lesion: analysis by intravascular ultrasound. Ann Cardiol Angeiol (Paris) 2012;61:20-26.

17. Falk E, Nakano M, Bentzon JF, Finn AV, Virmani R. Update on acute coronary syndromes: the pathologists' view. Eur Heart J 2013;34:719-28.

18. Burke AP, Kolodgie FD, Farb A, Weber D, Virmani R. Morphological predictors of arterial remodeling in coronary atherosclerosis. Circulation 2002;105:297-303.

19. Lanza GA, Crea F. Primary coronary microvascular dysfunction: clinical presentation, pathophysiology, and management. Circulation 2010;121:2317-25.

20. Mohri M, Koyanagi M, Egashira K, Tagawa H, Ichiki T, Shimokawa $\mathrm{H}$ et al. Angina pectoris caused by coronary microvascular spasm. Lancet 1998;351:1165-69.

21. Mahrholdt H, Wagner A, Deluigi CC, Kispert E, Hager S, Meinhardt $\mathrm{G}$ et al. Presentation, patterns of myocardial damage, and clinical course of viral myocarditis. Circulation 2006;114:1581-90.

22. Cuculi F, Togni M, Meier B. Myocardial infarction due to paradoxical embolism in a patient with large atrial septal defect. J Invasive Cardiol 2009;21:E184-E186.

23. Crump $R$, Shandling AH, Van Natta B, Ellestad $M$. Prevalence of patent foramen ovale in patients with acute myocardial infarction and angiographically normal coronary arteries. Am J Cardiol 2000;85:1368-70.

24. Sastry S, Riding G, Morris J, Taberner D, Cherry N, Heagerty $A$ et al. Young Adult Myocardial Infarction and Ischemic Stroke: the role of paradoxical embolism and thrombophilia (The YAMIS Study). J Am Coll Cardiol 2006;48:686-91.

25. Kang WY, Jeong MH, Ahn YK, Kim JH, Chae SC, Kim YJ et al. Korea Acute Myocardial Infarction Registry Investigators. Are patients with angiographically near-normal coronary arteries who present as acute myocardial infarction actually safe? Int J Cardiol 2011;146:207-12.

26. Larsen AI, Nilsen DW, Yu J, Mehran R, Nikolsky E, Lansky $A J$, et al. Long-term prognosis of patients presenting with ST-segment elevation myocardial infarction with no significant coronary artery disease (from the horizons-AMI trial). Am J Cardiol 2013;111:643-48.

27. Dey S, Flather MD, Devlin G, Brieger D, Gurfinkel $E P$, Steg PG, et al. . Sex-related differences in the presentation, treatment and outcomes among patients with acute coronary syndromes: the Global Registry of Acute Coronary Events. Heart 2009;95:20-26.

28. Patel MR, Chen AY, Peterson ED, Newby LK, Pollack $\mathrm{CV}$ Jr, Brindis RG, et al. Prevalence, predictors, and outcomes of patients with non-ST-segment elevation myocardial infarction and insignificant coronary artery disease: results from the Can Rapid risk stratification of Unstable angina patients Suppress ADverse outcomes with Early implementation of the ACC/AHA Guidelines (CRUSADE) initiative. Am Heart J 2006;152:641-47.

29. Roe MT, Harrington RA, Prosper DM, Pieper KS, Bhatt $D L$, Lincoff $A M$, et al. Clinical and therapeutic profile of patients presenting with acute coronary syndromes who do not have significant coronary artery disease. The platelet glycoprotein IIb/IIIa in unstable angina: receptor suppression using integrilin therapy (PURSUIT) trial investigators. Circulation 2000;102:1101-06.

30. Rossini R, Capodanno D, Lettieri C, Musumeci G, Limbruno $U$, Molfese $M$, et al. Long-term outcomes of patients with acute coronary syndrome and nonobstructive coronary artery disease. Am J Cardiol 2013;112:150-55. 